\title{
Effect of Carbon Content on Ti Inclusion Precipitated in Tire Cord Steel
}

\author{
Yuedong Jiang $^{1,2}$, Jialiu Lei ${ }^{1}$, Jing Zhang ${ }^{1}$, Rui Xiong ${ }^{1}$, Feng Zou ${ }^{1}$, Zhengliang Xue ${ }^{1}$ \\ ${ }^{1}$ Key Laboratory for Ferrous Metallurgy and Resources Utilization of Ministry of Education, Wuhan University of Science and \\ Technology, Wuhan, China; ${ }^{2}$ Research and Development Center of Wuhan Iron \& Steel Group, Wuhan, China. \\ Email: 710158466@qq.com
}

Received September $10^{\text {th }}, 2013$; revised October $4^{\text {th }}$, 2013; accepted October $20^{\text {th }}, 2013$

Copyright (c 2013 Yuedong Jiang et al. This is an open access article distributed under the Creative Commons Attribution License, which permits unrestricted use, distribution, and reproduction in any medium, provided the original work is properly cited.

\begin{abstract}
The precipitation of TiN inclusion during solidification of different carbon content of $0.72 \%, 0.82 \%$ and $0.95 \%$ in tire cord steel is thermodynamically studied respectively. The results show that the carbon content has obvious effect on TiN inclusion precipitated in tire cord steel of different strength levels. With the carbon content of tire cord steel increasing, the temperature before solidifying reduced gradually and the required activity product of titanium and nitrogen for TiN inclusion precipitation also declined gradually. With the same condition of initial $\mathrm{Ti}$ and $\mathrm{N}$ content in liquid steel, the size of TiN inclusion precipitated in tire cord steel of higher carbon content is bigger than that of lower carbon content. In order to control the harmful effects on processability of TiN inclusion precipitated in hypereutectoid tire cord steel of the ultra high strength level, the measures of smelting process must be taken to further reduce the titanium and nitrogen content in liquid steel.
\end{abstract}

Keywords: Hypereutectoid Tire Cord Steel; TiN Inclusion; Carbon Content; Thermodynamics

\section{Introduction}

The tire cord steel is a kind of high carbon steel, which is used for the production of car tyres meridian steel wire. With the car lightening and considering the safety of the car, the strength level of car tyre cord steel wire is improving. Before the 1990s, the mainstream brands of the tyre steel wire are SWRH62A and SWRH67A of ordinary strength grade $1750 \mathrm{MPa}$. Since the 1990s, the mainstream brands of the tyre steel wire are SWRH72A of high strength grade $1870 \mathrm{MPa}$. Entering the 21st century, the mainstream of the tire steel wire product is the hypereutectoid tire cord steel SWRH82A of the ultra high strength level and brands of a higher strength level in which carbon content reached $0.92 \%-0.95 \%$. In order to control the harmful effects of titanium inclusion in hypereutectoid tire cord steel on the drawing performance of wire rod, steelmakers should take tough measures of steelmaking and refining technology to remove the content of $\mathrm{Ti}$ and $\mathrm{N}$ in the molten steel to the limit as much as possible. In spite of this, in the condition of current steel production technology, the precipitation of titanium inclusion is still inevitable before solidifying [1]. In order to provide theoretical guidance to control TiN inclusion precipitated in the hypereutectoid tire cord steel of the ultra high strength level, the effect of carbon content on $\mathrm{Ti}$ inclusion precipitated in tire cord steel of different intensity levels is studied on the basis of thermodynamics in this paper.

\section{Temperature Changes in Solidifying Front of Tire Cord Steel}

The temperature in the front of solidifying $\left(T_{s-l}\right)$ of liquid steel is the solidification interface temperature, this temperature value is between the solidus temperature $\left(T_{s}\right)$ and the liquidus temperature $\left(T_{l}\right)$, It related with the solidification rate $(g)$ of liquid-solid two phase region. The temperature in the front of solidifying is calculated according to formula (1) [2]:

$$
T_{s-l}=T_{0}-\frac{T_{0}-T_{l}}{1-g \frac{T_{l}-T_{s}}{T_{0}-T_{s}}}
$$

In formula (1) $T_{0}$ is the melting point of $\mathrm{Fe} 1538^{\circ} \mathrm{C}$, the liquidus temperature $\left(T_{l}\right)$ and the solidus temperature $\left(T_{s}\right)$ are calculated according to formula (2) and formula (3): 


$$
\begin{aligned}
T_{l} & =1538-65 w[C]-8 w[S i]-5 w[M n] \\
& -20 w[T i]-30 w[P]-25 w[S] \\
& -1300 w[H]-90 w[N]-80 w[O] \\
T_{S} & =1538-175 w[C]-20 w[S i] \\
& -30 w[M n]-40 w[T i]-280 w[P] \\
& -575 w[S]-160 w[O]
\end{aligned}
$$

The components of tire cord steel used for calculation are shown in Table 1.

According to the components of tire cord steel in Table 1 the liquidus temperature $\left(T_{l}\right)$ and solidus temperature $\left(T_{s}\right)$ can be calculated, as shown in Table 2 . With the increase of carbon content, the temperature difference of liquidus and solidus become large.

The relationship between the temperature in the front of solidifying $\left(T_{s-l}\right)$ and solidification rate $(g)$, as shown in Figure 1.

Figure 1 shows that the temperature in the front of solidifying $\left(T_{s-l}\right)$ decreased along with the development of the solidification process. When the solidification rate is the same, the higher carbon content in the tire cord steel, the lower the temperature in the front of solidifying.

\section{Effect of Carbon Content on Ti Inclusion Precipitated in Tire Cord Steel}

Due to the solidification segregation of the solute elements during solidification process, $\mathrm{Ti}$ and $\mathrm{N}$ are enriched in the solidifying front continuously, when the activity product of $\mathrm{Ti}$ and $\mathrm{N}$ is greater than the balanced activity product of TiN precipitation, TiN inclusion will precipitate according to the following formula:

$$
\begin{aligned}
& {[T i]+[N]=\operatorname{TiN}_{(S)}} \\
& \Delta G^{0}=-291000+107.97 T
\end{aligned}
$$

$$
\lg K_{T i N}=5.64-15220 / T
$$

In formula (5), $K_{T i N}$ is the equilibrium activity product of TiN precipitation, which related with the temperature $T_{s-l}$ in the front of solidifying. With the solidification rate $(g)$ of liquid-solid two phase region increase, temperature in the front of solidifying dropped and the value of $K_{\text {TiN }}$ calculated according to formula (5) declined correspondingly.

The actual activity product of $\mathrm{Ti}$ and $\mathrm{N}$ in the solidifying front is:

$$
Q_{T i N}=f_{T i} \cdot f_{N} \cdot w[T i] \cdot w[N]
$$

In formula (6), $f_{T i}$ and $f_{N}$ are the activity coefficients of $\mathrm{Ti}$ and $\mathrm{N}$ at the temperature of solidifying front, which can be calculated according to formula (7) and formula (8):

Table 1. Chemical composition of high carbon tire cord steel.

\begin{tabular}{cccccccc}
\hline Steel grade & $\mathrm{C}$ & $\mathrm{P}$ & $\mathrm{S}$ & $\mathrm{Si}$ & $\mathrm{Mn}$ & $\mathrm{N}$ & $\mathrm{Ti}$ \\
\hline $72 \mathrm{~A}$ & 0.72 & 0.01 & 0.008 & 0.2 & 0.5 & 0.004 & 0.0006 \\
82A & 0.82 & 0.01 & 0.008 & 0.2 & 0.5 & 0.004 & 0.0006 \\
95A & 0.95 & 0.01 & 0.008 & 0.2 & 0.5 & 0.004 & 0.0006 \\
\hline
\end{tabular}

Table 2. The value of $T_{l}$ and $T_{s}$ for tire cord steel of different carbon content.

\begin{tabular}{cccc}
\hline Steel grade & $T_{l}$ & $T_{s}$ & $T_{l}-T_{s}$ \\
\hline $72 \mathrm{~A}$ & 1486 & 1386 & 100 \\
$82 \mathrm{~A}$ & 1480 & 1368 & 112 \\
$95 \mathrm{~A}$ & 1472 & 1345 & 127 \\
\hline
\end{tabular}

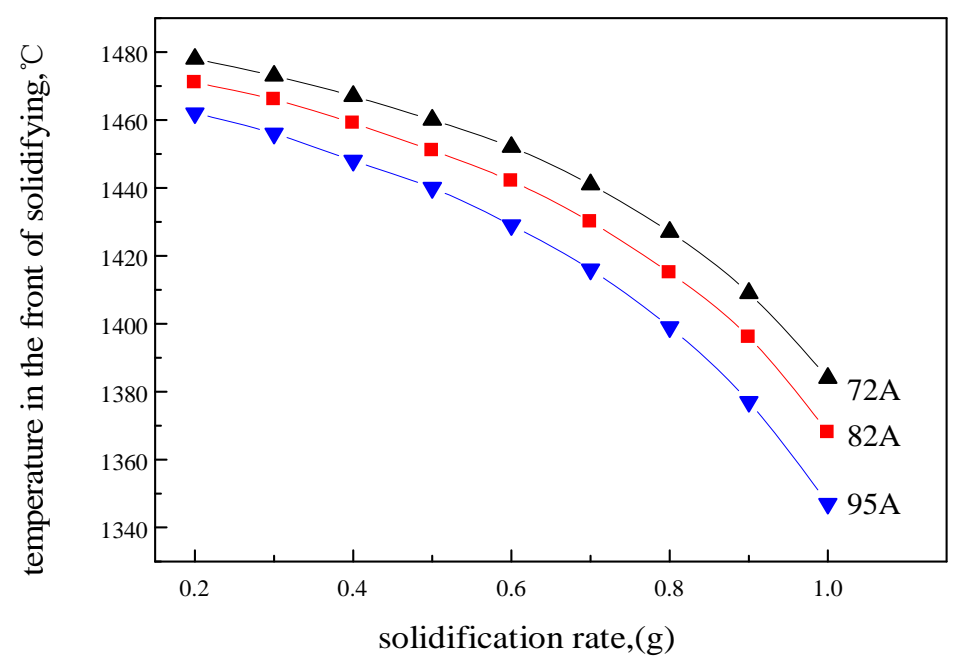

Figure 1. Relationship between the temperature in the front of solidifying and solidification rate at different carbon content of tire cord steel. 


$$
\begin{aligned}
& \lg f_{T i}=\left(2557 / T_{s-l}-0.365\right) \lg f_{T i(1873)} \\
& \lg f_{N}=\left(3280 / T_{s-l}-0.75\right) \lg f_{N(1873)}
\end{aligned}
$$

In formula (7) and formula (8), $f_{T i(1873)}$ and $f_{N(1873)}$ are the activity coefficients of elements $\mathrm{Ti}$ and $\mathrm{N}$ at $1873 \mathrm{~K}$ respectively:

$$
\begin{aligned}
& \lg f_{T i(1873)}=\sum e_{T i}^{j} w[j] \\
& \lg f_{N(1873)}=\sum e_{N}^{j} w[j]
\end{aligned}
$$

The interaction coefficients $e_{T i}^{j}$ and $e_{N}^{j}$ at $1873 \mathrm{~K}$ can be obtained by literature $[5,6]$.

Since the solute elements in the solidifying front enriched during solidification process continuously, so $w[j]$ can be calculated according to formula (9) and formula (10) [7]. It can be seen that $w[j]$ is the function of solidification rate $(g)$.

$$
\begin{aligned}
& w[j]=w[j]_{0}(1-g)^{k-1} \\
& w[j]=\frac{w[j]_{0}}{g(k-1)+1}
\end{aligned}
$$

Formula (11) is used to calculate the quality percentage content of $\mathrm{Ti}, \mathrm{Si}, \mathrm{Mn}$ in the solidifying front and formula (12) is used to calculate the quality percentage content of $\mathrm{C}, \mathrm{N}, \mathrm{P}, \mathrm{S}$ in the solidifying front; $w[j]_{0}$ is the initial percentage of solute element $j$ in liquid steel. $k$ is the equilibrium partition coefficients between liquid steel and $\gamma$-Fe which can be obtained by literature $[8,9]$.

The actual activity product $Q_{T i N}$ of $\mathrm{Ti}$ and $\mathrm{N}$ in the solidifying front of liquid steel can be calculated by formula (6) - formula (12), When the actual activity product $Q_{T i N}$ of $\mathrm{Ti}$ and $\mathrm{N}$ in the solidifying front is greater than that of the equilibrium activity product $K_{\text {TiN }}$, TiN inclusion will precipitate in the solidifying front. If the initial

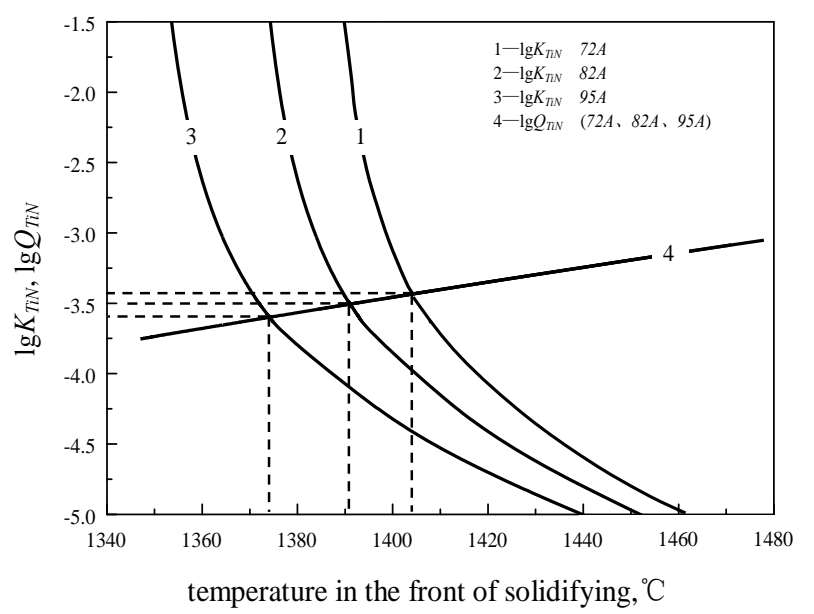

(a)
Ti, N content of tire cord steel are $0.0006 \%$ and $0.004 \%$ respectively, the temperature in the front of solidifying and solidification rate for 72A, 82A, 95A, when TiN inclusion precipitated in the solidifying front are shown in Figure 2.

Figure 2 shows that with the carbon content in tire cord steel increase, the temperature in the front of solidifying dropped when TiN inclusion precipitated during solidification and the required equilibrium activity product is also declined (Figure 2(a)). In addition, with the increase of carbon content in the tire cord steel, TiN inclusion is earlier to precipitate in the solidifying front (Figure 2(b)), Therefore, TiN inclusion is also more easily to grow up.

In conclusion, the carbon content has obvious effect on TiN inclusion precipitated in tire cord steel of different strength levels. The higher the carbon content in molten steel, the easier the TiN inclusion will precipitate and grow up during solidification process.

Therefore, in order to control the size of TiN inclusion precipitated in hypereutectoid tire cord steel of ultra high strength level, more strict measures of steelmaking and continuous casting process must be taken to further reduce the initial titanium and nitrogen content in liquid steel. Because the effect of $\mathrm{N}$ on the grown up of TiN inclusion is bigger than that of $\mathrm{Ti}$ [1], Therefore, it is particularly important to further reduce the $\mathrm{N}$ content in hypereutectoid tire cord steel.

The Ti content in the high carbon tire cord steel in molten steel can be reduced effectively through the following measures in the production practice; (1) reducing the $\mathrm{TiO}_{2}$ content in blast furnace burden and silicon content in hot metal; (2) control of carbon conent and temperature in the bof(basic oxygen furnace) endpoint; (3) control of the amount of converter slag; (4) material control of LF(ladle furnace) refining slag and the $\mathrm{TiO}_{2}$ content

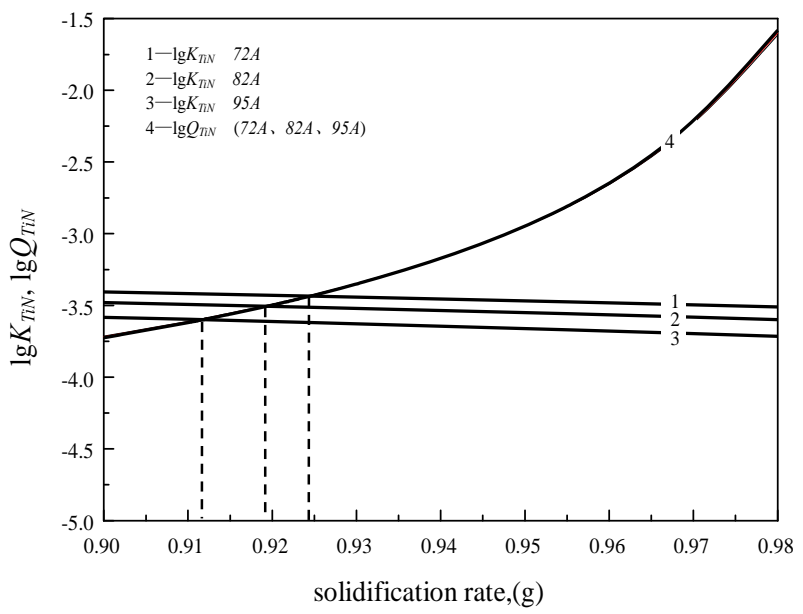

(b)

Figure 2. The effect of carbon content on TiN inclusion precipitated in tire cord steel. 
in the tundish flux. The control of nitrogen in the tire cord steel are mainly from the following several aspects: (1) reducing the reblowing operation in endpoint; (2) using pre-melted slag to cover the liquid steel and reducing the inspiration during converter tapping; (3) using low nitrogen carburant; (4) control of LF refining slag and argon stirring; (5) further reducing the content of oxygen and nitrogen in liquid steel by vacuum treatment.

\section{Conclusion}

(1) The temperature before solidifying $\left(T_{s-l}\right)$ decreased along with the development of the solidification process. When the solidification rate is the same, the higher the carbon content in the tire cord steel is, the lower the temperature before solidifying is.

(2) The carbon content has an obvious effect on TiN inclusion precipitated in tire cord steel of different strength levels. The higher the carbon content is in the molten steel, the easier the TiN inclusion will precipitate and grow up during the solidification process.

(3) In order to control the size of TiN inclusion precipitated in hypereutectoid tire cord steel of the ultra high strength level, more strict measures of steelmaking and the continuous casting process must be taken to further reduce the initial titanium and nitrogen content in liquid steel, especially the $\mathrm{N}$ content.

\section{Acknowledgements}

The author gratefully acknowledges the financial support for this work from the Science research plan (No. 201210321098) of Wuhan Science and Technology Bu- reau, China.

\section{REFERENCES}

[1] J. L. Lei, Z. L. Xue and Y. D. Jiang, "Study on TiN Precipitation during Solidification of Hypereutectoid Tire Cord Steel,” Metalurgia International, Vol. 17, No. 9, 2012, pp. 10-15.

[2] I. Ohnaka, "Mathematical Analysis of Solute Redistribution during Solidification with Diffusion in Solid Phase," Transaction ISIJ, Vol. 26, No. 12, 1986, pp. 1045-1051.

[3] E. P. Chen, "Calculation Method and Empirical Formula for Melting Point of Fe-Based, Ni-Based and Co-Based Alloy,” Special Steel, Vol. 13, No. 2, 1992, pp. 25-30.

[4] J. Fu, J. Zhu and L. Di, "Research on Precipitation Regularity of TiN in Micro Alloy Steel," Acta Metallurgica Sinica, Vol. 36, No. 8, 2000, pp. 801-804.

[5] L. K. Liang, "Metallurgical Thermodynamics and Kinetics," Northeast University Press, Shenyang, 1990, pp. 30-31.

[6] Z. T. Ma and J. Dieter, "Characteristic of Oxide Precipitation and Growth during Solidification of Deoxidized Steel,” ISIJ International, Vol. 1, No. 38, 1988, pp. 4652.

[7] Y. Qu, "Steelmaking Principles,” Metallurgical Industry Press, Beijing, Vol. 8, 1983, pp. 294-313.

[8] Y. Ueshima, S. Mizoguchi and T. Matsumiya, “Analysis of Solute Distribution in Dendrites of Carbon Steel with $\delta / \gamma$ Transformation Solidification," Metallurgical Transaction, Vol. 17B, No. 4, 1986, pp. 845-859.

[9] P. A. Manohar, D. P. Dunne and T. Chandra, "Grain Growth Predictions in Microalloyed Steels," ISIJ International, Vol. 36, No. 2, 1996, p. 194. http://dx.doi.org/10.2355/isijinternational.36.194 